\title{
Peran Ekstrakurikuler Pramuka Dalam Membentuk Karakter Peduli Sosial Siswa
}

\author{
Suri Rahmayani1*, Zaka Hadikusuma Ramadan²
}

1,2 Jurusan Pendidikan Guru Sekolah Dasar, Universitas Islam Riau, Pekanbaru, Indonesia

\section{A R T I C L E I N F O}

Article history:

Received August 09, 2021

Revised August 15, 2021

Accepted September 30, 2021

Available online October 25, 2021

Kata Kunci:

Karakter Peduli Sosial,

Kegiatan Pramuka

Keywords:

The Socially Concerned

Character, Scout Activities

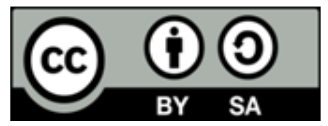

This is an open access article under the CC BY-SA license.

Copyright $(\subset 2021$ by Author. Published by Universitas Pendidikan Ganesha.

\begin{abstract}
A B S T R A K
Penurunan perilaku sosial terhadap anak kerap terjadi pada masa sekarang, beberapa individu lebih sibuk mengabadikan momen sebut dengan memvidio, memotret, atau menyebarkan pada jejaring media sosial. Oleh sebab itu diperlukan wadah untuk pembentukan karakter, yang mana pembentukan karakter berawal dari keluarga, lingkungan serta sekolah. Tujuan penelitian ini untuk menganalisis peran ekstrakurikuler pramuka dalam membentuk karakter peduli sosial di sekolah dasar. Penelitian ini menggunakan metode penelitian kualitatif deskriptif dengan sumber data primer dari siswa, kepala sekolah seta pembina pramuka. Teknik pengumpulan data menggunakan teknik wawancara, dan dokumentasi. Untuk memperoleh keabsahan data yang objektif, maka teknik analisis menggunakan uji kreadibilas triangulasi sumber. Penelitian ini menggunakan teknik Miles dan Huberman yaitu data collection, reduksi data, penyajian data dan penyimpulan data. Hasil penelitian ini menunjukkan ektrakurikuler pramuka berperan untuk membentuk karakter peduli sosial pada siswa hal tersebut ditunjukan dengan kegiatan kepramukaan yang bertujuan membangun karakter siswa, upaya yang dilakukan oleh pembina serta dukungan warga sekolah. Implikasi penelitian ini diharapkan dapat meningkatkan sikap peduli sosial peserta didik maupun karakter lainnya dalam mematuhi peraturan. Selain itu dapat meningkatkan sikap saling menghormati dan menghargai baik sesama teman maupun kepada pembina dan guru.
\end{abstract}

\section{A BS TR A C T}

The decline in social behavior towards children often occurs nowadays, some individuals are busier capturing the moment by making videos, taking pictures, or spreading them on social media networks. Therefore, a forum for character formation is needed, where character formation starts from the family, environment and school. The purpose of this study was to analyze the role of scout extracurriculars in shaping the character of social care in elementary schools. This study uses a descriptive qualitative research method with primary data sources from students, school principals and scout coaches. Data collection techniques use interview techniques, and documentation. To obtain the validity of the objective data, the analysis technique used the triangulation of source credibility test. This study uses Miles and Huberman techniques, namely data collection, data reduction, data presentation and data inference. The results of this study indicate that extracurricular scouts play a role in shaping the character of social care in students, this is indicated by scouting activities that aim to build student character, the efforts made by the coaches and the support of school residents. The implications of this research are expected to increase the social care attitude of students and other characters in complying with regulations. In addition, it can increase mutual respect and respect for fellow friends as well as for coaches and teachers.

\section{PENDAHULUAN}

Pendidikan karakter merupakan usaha sadar yang terencana bertujuan untuk menanamkan nilai moral agar terbentuk akhlak yang baik (Gazali et al., 2019; Mashar, 2015; Sasmito \& Mustadi, 2015). Pendidikan karakter secara esensial tercermin dalam fungsi dan tujuan pendidikan sebagaimana dicantumkan dalam Undang-undang No. 20 Tahun 2003 tentang SistemPendidikan Nasional Pasal 3 bahwa pendidikan nasional berfungsi mengembangkan kemampuan dan membentuk watak serta peradaban bangsa yang bermartabat dalam rangka mencerdaskan kehidupan bangsa, bertujuan untuk berkembangnya potensi peserta didik agar 
menjadi Manusia yang beriman dan bertakwa kepada Tuhan Yang Maha Esa, berakhlak mulia, sehat, berilmu, cakap, kreatif, mandiri, dan menjadi warga negara yang demokratis serta bertanggung jawab (R. Wahyuni \& Erdiyanti, 2020; S. Wahyuni et al., 2015). Dengan demikian, akan terbangun generasi bangsa yang tidak hanya cerdas, namun juga berkarakter baik. Karakter yang paling penting dalam kehidupan yang berkelanjutan dengan generasi mendatang adalah memanfaatkan lingkungan secara bertanggung jawab. Hal ini sangat perlu diperhatikan, sebab jangan sampai terjadi memanfaatkan lingkungan dengan cara yang serakah; kekayaan alam dikeruk sebanyak-banyaknya tanpa memperhatikan kepentingan generasi mendatang; hutan dibabat habis tanpa melakukan penanaman kembali yang memadai. Pendidikan karakter yang efektif menggunakan pendekatan yang fleksibel dan luas untuk mendukung program pendidikan karakter di sekolah ada beberapa hal yang menunjang yaitu pengintegrasian mata pelajaran, pengembangan diri dalam kehidupan sehari-hari, keteladanan serta pengkondisian (Dozan \& Fitriani, 2020; Nurdin et al., 2021; Putry, 2019).

Namun kenyataan saat ini terdapat bentuk dekadensi moral generasi muda bangsa. Dekadensi tersebut setidaknya menggambarkan begitu rapuhnya karakter diri generasi muda Indonesia(Putry, 2019; Sufanti et al., 2021; Tanto et al., 2019). Selain itu, kepedulian sosial anak menurun (Arif et al., 2021; Syafitri, 2020). Faktor yang menyebabkan turunnya kepedulian sosial kepada anak yaitu bermain internet, sangat mudahnya untuk mengakses sesuatu informasi menjadikan anak lupa waktu dan kurang bersosialisasi dengan lingkungan sekitar (Agustika, 2020; Kharisma Bismi Alrasheed \& Aprianti, 2011; Widiyono, 2020). Sarana hiburan (game), dengan perkembangan teknologi sarana hiburan berbentuk game telah menjauhkan anak anak dari kegiatan sosial seperti bermain dengan teman sejawat (Amania et al., 2021; Oktavia \& Mulabbiyah, 2019). Tayangan televisi, dengan banyaknya sinetron yang tidak mendidik menjadikan anak anak cenderung meniru perilaku tersebut, Masuknya budaya barat, budaya barat bertolak belakang dengan budaya timur menjadikan seseorang cenderung lebih peduli dengan dirinya sendiri. beberapa individu lebih sibuk mengabadikan momen sebut dengan memvidio, memotret, atau menyebarkan pada jejaring media sosial (Syafitri, 2020). Banyaknya kasus krisis karakter ini membuat pendidik harus memaksimalkan pendidikan karakter yang ada.

Peningkatan karakter ini dapat dilakukan melalui kegiatan Ekstrakurikuler. Kondisi ini merupakan momentum yang tepat untuk melaksanakannya sebagai perwujudan dari gagasan pendidikan karakter agar tujuan dari pendidikan karakter dapat tercapai, dan mempunyai pengaruh terhadap belajar peserta didik (Fauzi \& Khoiriyah, 2018; Gazali et al., 2019). Kegiatan Ekstrakulikuler ialah kegiatan yang dilaksanakan di luar jam pelajaran berfungsi untuk mengembangkan minat dan bakat siswa, menjadikan siswa lebih aktif, kreatif dan percaya diri (Sari et al., 2021; Sularso, 2017). Pembentukan karakter dapat dibentuk dimulai dari keluarga, lingkungan dan sekolah. Pendidikan disekolah dapat membentuk kepribadian siswa, menjadikan siswa sosok yang lebih baik. Biasanya aktivitas ekstrakurikuler ini dilaksanakan diluar jam belajar wajib di sekolah (Azizi, 2020; Maulida et al., 2021). Salah satu contoh ekstrakurikuler di Sekolah Dasar yaitu ekstrakurikuler kepramukaan. Banyak karakter yang dapat ditanamkan dalam kegiatan ektrakurikuler pramuka, dengan kegiatan-kegiatan yang positif diharapkan dapat mewujudkan siswa yang peduli terhadap sosial mereka dan dapat membenuk karakter peduli social (Hero, 2020; Nurdin et al., 2021). Tujuan dari ektrakurikuler pramuka dapat membentuk kepribadian seperti kepribadian beriman, bertakwa, berakhlak mulia, berjiwa patriotik, taat hukum, disiplin, menjunjung tinggi nilai nilai luhur bangsa, berkecakapan hidup, seat jasmani dan rohani, menjadi warga Negara yang berjiwa pancasila, memiliki kepedulian terhadap sesama hidup dan lingkungan alam (Juwantara, 2019; Laksono, 2018). Ektrakurikuler pramuka sangat erat kaitannya dalam membentuk karakter siswa.

Beberapa temuan sebelumnya menyatakan gerakan pramuka hadir sebagai salah satu alat pembentukan karakter dalam dunia pendidikan yang terbentuk kegiatan ektrakurikuler di sekolah(Gazali et al., 2019; Nurdin et al., 2021; Nurfajriah et al., 2021). Kegiatan kepramukaan sangat berkontribusi dalam meningkatkan kecerdasan emosional seseorang, kecerdasan emosional dapat membentuk sikap peduli sosial seseorang yang mana dalam kegiatan kepramukaan diajarkan untuk saling tolong menolong dan gotong royong yang mana sifat tersebut sangat diperlukan saat seseorang menjadi bagian dari masyarakat (Amreta, 2018; Juwantara, 2019). Kepedulian sosial yakni rasa tanggungjawab terhadap kesulitan yang dihadapi orang lain, dalam hal ini seseorang terdorong melakukan sesuatu untung membantu oranglain menghadapi masalah tersebut (Arif et al., 2021; Musyarofah, 2018). Berdasarkan ulasan di atas penelitian ini mengkaji tentang peran ektrakurikuler pramuka dalam membentuk karakter peduli sosial siswa di karenakan ektrakurikuler pramuka erat kaitannya dengan pembembentukan karakter siswa hal tersebut dapat dilihat dari landasan dasar serta tujuan ektrakurikuler pramuka dan ektrakurikuler pramuka bersifat luas yang mana untuk menjadi seorang pramuka tidak melihat usia dari seseorang anak anak, remaja bahkan dewasa. Kegiatan kegiatan kepramukaan juga sangat bervariatif dan cenderung saling menolong baik itu menolong anggota regu atau kelompok bahkan masyarakat sekitar. Penelitian ini bertujuan untuk menganalisis peran ektrakurikuler pramuka dalam membentuk karakter peduli sosial siswa di sekolah dasar. Adanya penelitian ini diharapkan dapat mengembangkan berbagai karakter siswa untuk menanamkan berbagai karakter sejak dini. 


\section{METODE}

Jenis penelitian ini adalah deskriptif kualitatif yang mana dalam penulisan pelaporan penelitian berbentuk fakta tentang peran ektrakurikuler pramuka di Sekolah Dasar. Alur penelitian berawal dari wawancara awal yang dilakukan tentang kegiatan ekstakurikuler dalam pembentukan karakter peduli sosial siswa yang meliputi tiga fokus penelitian yaitu bagaimana pelaksanaan ektrakurikuler pramuka, peran ektrakurikuler dalam membentuk sikap peduli sosial siswa serta faktor yang memperngaruhi kegiatan ekstrakurikuler pramuka dalam membentuk karakter peduli sosial. Wawancara dilakukan dengan pembina pramuka, Kepala Sekolah dan Siswa. Wawancara dengan Pembina meliputi program kegiatan serta perilaku anak selama kegiatan kepramukaan dan siswa tentang kegiatan yang pernah mereka lakukan selama mengikuti kegiatan kepramukaan dalam pembentukan karakter peduli sosial siswa, wawancara dengan Kepala Sekolah menggali informasi bentuk dari dukungan sekolah dalam membentuk karakter peduli sosial serta dukungan dalam kegiatan ektrakurikuler pramuka dan wawancara yang dilakukan dengan siswa bertujuan untuk menggali informasi tentang pengalaman siswa serta megkonfirmasi pernyataan wawancara dari pembina maupun Kepala Sekolah. Hal ini bertujuan agar mendapatkan data yang konkret dalam peran ektrakurikuler pramuka membentuk sikap peduli sosial. Teknik pengumpulan data yang digunakan adalah wawancara dan dokumentasi. Observasi tidak dilakukan dikarenakan kegiatan tidak bisa dilakukan secara normal dikarenakan pandemic Covid_19. Objek penelitian yaitu siswa SDN 001 Pantai Raja Kecamatan Perhentian Raja, Kabupaten Kampar Provinsi Riau. Untuk memperoleh keabsahan data yang objektif dalam penelitian kualitatif maka, peneliti menggunakan triangulasi. Menurut moleong (2017) "Triangulasi merupakan teknik pemeriksaan keabsahan data yang menggunakan sumber diluar data tersebut atau membandingkan triangulasi dengan sumber data". Penelitian ini menggunakan teknik analisis data Miles and Huberman. penyajian data dalam analisis data ini yaitu: Data collection/pengumpulan data, Reduksi data (data reduction), penyajian data (data display) dan Penarikan kesimpulan/verifikasi.

\section{HASIL DAN PEMBAHASAN}

Hasil

Berdasarkan hasil wawancara yang dilakukan pada kepala sekolah, pembina pramuka dan siswa pelaksanaan ektrakurikuler pramuka merupakan ektrakurikuler wajib dan seluruh siswa wajib untuk mengikuti ektrakurikuler pramuka sesuai dengan Permendikbud Nomor 63 tahun 2014 yang menyatakan bahwa ektrakurikuler pramuka merupakan ektrakuriler wajib. Pandemi covid_19 yang terjadi melanda Indonesia dan pemerintah mengeluarkan surat edaran nomor 15 tahun 2020 tentang pedoman penyelenggaraan belajar dari rumah, pelaksanaan ekstrakurikuler pramuka untuk saat ini tidak dapat dilaksanakan secara normal dikarenakan pandemi covid_19. Pelaksanaan ektrakurikuler pramuka sebelum terjadinya pandemi covid_19 dilaksanakan setiap hari sabtu sore pukul 14.00 wib. Anggota pramuka di Sekolah Dasar terdiri dari golongan siaga dan golongan penggalang.

Pelaksanaan kegiatan ektrakurikuler pramuka sebelum terjadi pandemi covid_19 meliputi latihan setiap minggunya yang membahas materi tentang baris berbaris (PBB), Sejarah kepramukaan, morse, semaphore, kompas, tali temali, sandi, dan pertolongan pertama pada kecelakaan (P3K). Kode morse adalah sistem yang mewakili huruf, angka, dan tanda baca dengan menggunakan sinyal kode yang diciptakan oleh Samuel Morse dan Alfred Vail, semaphore merupakan cara mengirimkan pesan dengan media sepasang bendera, kompas merupakan alat untuk menetapkan arah mata angin, tali temali merupakan ilmu yang mempelajari tentang penggunaan tali, simpul, anyaman dan ikatan beserta cara perawatannya, kata sandi berasal dari bahasa Sansekerta yang artinya rahasia, pertolongan pertama dapat menyelamatkan jiwa manusia.Mengikuti perlombaan seperti lomba lintas alam, mengikuti perkemahan tingkat kecamatan dan ikut membantu warga sekitar bergotong royong. Selama pandemi terdapat diskusi ringan antara pembina serta siswa melalui whatsapp grup. Saat pandemi siswa ikut serta menyukseskan program kegiatan yang dilakukan oleh dewan kerja ranting (DKR) dengan ikut menyumbangkan dana untuk membantu membeli masker dan dibagikan pada masyarakat. Materi dan kegiatan pramuka menarik dan menyenangkan serta seluruh kegiatan mengembangkan nilai karakter. Kegiatan ekstrakurikuler pramuka juga merupakan serangkaian program kegiatan belajar mengajar untuk meningkatkan cakrawala pandang peserta didik menumbuhkan bakat dan minat serta semangat pengabdian kepada masyarakat (Gazali et al., 2019; Nurdin et al., 2021). Kegiatan pramuka itu sendiri memiliki kode penghormatan dan pengabdian yakni suatu norma atau nilai-nilai luhur dalam kehidupan (Amri, 2018; Hero, 2020). Jika peserta didik yang telah mengikuti pendidikan pramuka dan mereka bisa merealisassikan di dalam kehidupan sehari-hari sesuai dengan kode kehormatan kepramukaan, maka peserta didiknya pun akan memiliki karakter yang baik dalam diri mereka.

Seluruh kegiatan pramuka dapat membentuk karakter siswa dan hampir seluruh kegiatan pramuka dapat membentuk karakter peduli sosial siswa. Aktivitas-aktivitas pramuka dalam membentu karakter peduli sosial siswa antara lain. Pertama, aktivitas dalam kegiatan upacara, nilai peduli sosial terhadap siswa dapat tertanam saat kegiatan upacara yaitu, seperti bekerjasama dalam pelaksanaannya agar tepat dengan rancangan 
kegiatan yang disiapkan. Kedua, aktivitas dalam aktivitas tali temali, yaitu siswa bekerjasama dalam membuaat simpul dan cepat serta penuh ketelitian sehingga bisa diselesaikan. Hal ini menanamkan kepedulian sosial yang tinggi kepada siswa. Ketiga, aktivitas kegiatan baris berbaris, sikap peduli sosial disini tampak dengan memperhatikan teman sekitar agar saat kegiatan baris berbaris, saling mengingatkan satu sama lain. Hal tersebut salah satu contoh bahwa dalam kegiatan baris berbaris dapat meningkatkan kepedulian sosial siiswa dari hal yang kecil. Keempat, Aktivitas dalam berkemah yaitu salah satu kegiatan yang penting. Berkemah ini dapat meningkatkan kepedulian siswa karena dengan berkemah siswa bekerjasama. Tujuan dari berkemah ini untuk membina dan mengembangkan ketahanan mental, moral, emosional, intelektual, dan lainnya. Kepedulian sosial peserta didik memang harus diperhatikan karena kepedulian sosial merupakan kunci awal pembentukan karakter yang lainnya bagi peserta didik (Arif et al., 2021; Patria et al., 2021). Kepedulian sosial yang diajarkan dalam kegiatan pramuka memiliki peranan penting dalam membentuk peserta didik memiliki karakter yang baik dalam lingkungannya (Amri, 2018; Juwantara, 2019; Pangestika \& Sabardila, 2021). Oleh karena itu tujuan akhirnya adalah pembentukan kepribadian, budi pekerti, akhlak mulia, dan memiliki kecakapan hidup.

Hal ini selaras dengan pernyataan pembina pramuka serta pernyataan siswa berdasarkan pengalaman siswa bahwa peranan ektrakurikuler pramuka dalam kegiatan membentuk karakter peduli sosial. Pertama, pada implementasinya kegiatan kepramukaan mengajarkan siswa peduli dengan kegiatan-kegiatan dari hal kecil, jika ada teman yang sakit maka akan di jenguk. Hal tersebut dilakukan dengan cara siswa mengumpulkan uang kas saat latihan berlangsung salah satunya digunakan untuk menjenguk teman yang sakit. Kedua, saat kegiatan perkemahan setiap anggota pramuka saling menjaga satu dengan lainnya, jika ada teman yang sakit sama-sama dijaga, saling membantu saat membangun tenda, merapikan tenda, memasak selama perkemahan dan lain lain. Ketiga, pada kegiatan baris berbaris, anggota pramuka saling menjaga agar tetap kompak dengan saling menjaga barisan sesuai dengan aba-aba, mengingatkan teman yang jika ada salah dan belajar untuk mengalah dengan rasa egois dari diri sendiri. Keempat, pada kegiatan lintas alam, saat kegiatan lintas alam anggota pramuka saling membentuk dalam menyelesaikan rintangan jika ada, saling bekerja sama dan menjaga agar tidak ada anggota lain yang mengalami kesusahan sendiri. Kelima, kegiatan yang berhubungan dengan masyarakat yang mana anggota pramuka juga ikut berkontribusi dalam membantu masyarakat seperti bergotong royong bersama masyarakat. Keenam, anggota pramuka disekolah juga ikut serta dalam memajukan sekolah dengan saling bergotong royong menjaga kebersihan bersama. Ketujuh, anggota pramuka dengan kegiatan yang telah dilakukan cenderung disaat membantu sesama, disaat teman terjatuh maka akan membantu anak tersebut. Menjadi seseorang yang tidak menyetujui perundungan dan cenderung melindungi teman yang dirundung oleh teman yang lain. Kedelapan, disaat kasus kasus berkelahi di sekolah anggota pramuka dapat untuk melerai dan membantu temannya untuk saling memaafkan. Dalam hal ini, peran pembina pramuka sebagai mitra atau pembimbing, memberikan dukungan dan memfasilitasi peserta didik dengan kegiatan yang modern, menarik, dan menantang (Laksono, 2018; Nurdin et al., 2021; Pangestika \& Sabardila, 2021). Menciptakan kegiatan yang menarik ini diharapkan dapat membentuk karakter siswa yang mengikuti kegiatan kepramukaan.

Kegiatan ektrakulikuler pramuka menerapkan berbagai metode. Metodenya antara lain: pengamalan kode kehormatan pramuka pada setiap kegiatan; kegiatan belajar sambil melakukan, berkelompok, bekerja sama, dan berkompetisi kegiatan di alam terbuka seperti perkemahan; penghargaan berupa tanda kecakapan bantara dan laksana serta satuan terpisah ambalan putra dan putri. Sehingga ektrakurikuler pramuka dapat berjalan dengan baik namun, dalam pelaksanaannya kegiatan ektrakurikuler pramuka memiliki beberapa hambatan, hambatan yang paling utama yaitu dikarenakan pandemi covid_19 latihan kepramukaan tidak dapat dilaksanakan secara tatap muka bahkan vacum untuk sementara waktu, kurangnya sarana dan prasarana yang menunjang kegiatan kepramukaan seperti jumlah beberapa kelengkapan perkemahan serta penunjang materi tentang kepramukaan, administrasi yang kurang lengkap seperti serta turunnya semangat anak dan ketertarikan anak terhadap kegiatan pramuka dikarenakan situasi pandemi covid_19. Terdapat faktor pendukung dalam pelaksanaan ektrakurikuler pramuka seperti kegiatan yang menyenangkan, warga sekolah yang mendukung kegiatan ektrakurikuler dengan mengingatkan setiap waktu kepramukaan, pembina pramuka yang tetap kreatif dalam berkegiatan dimasa pandemi (Nurfajriah et al., 2021; Prihanawati \& Hidayah, 2018). Hal ini dibuktikan dengan dalam situasi pandemi masih ada siswa yang berkegiatan walaupun secara online, seperti mendemonstrasikan cuci tangan lalu di vidiokan, membantu menyukseskan program dewan kerja ranting untuk menggalang dana dengan memberikan sumbangan dana, hal ini membuktikan bahwa pada masa pandemi walaupun tidak latihan seperti biasa siswa tetap berkegiatan. Implikasi penelitian ini diharapkan dapat meningkatkan sikap peduli sosial peserta didik maupun karakter lainnya dalam mematuhi peraturan. Selain itu dapat meningkatkan sikap saling menghormati dan menghargai baik sesama teman maupun kepada pembina dan guru.

\section{SIMPULAN}

Pramuka memiliki dasar serta tujuan yang jelas untuk menanamkan karakter pada siswa sejalan dengan 18 karakter yang ditanamkan dalam kurikulum 2013 dan dasar kepramukaan ini sudah ada sejak lama 
berdasarkan pada kode kehormatan Trisatya dan Dasa Darma dan diatur dalam undang undang termasuk karakter peduli sosial. Peran ekstrakurikuler pramuka dalam membentuk karakter peduli sosial siswa yaitu setiap kegiatan kepramukaan dapat menanamkan karakter terutama karakter peduli sosial, seperti kegiatan perkemahan, gotong royong bersama masyarakat, bahkan di saat pandemi siswa ikut berkontribusi membantu masyarakat dengan caranya dan dari hal terkecil. Warga sekolah yang mendukung dan kegiatan pramuka yang sudah di wajibkan oleh pemerintah menjadikan pembentukan karakter terutama karakter peduli sosial terbentuk secara maksimal. Pembiasaan baik pada setiap kegiatan kepramukaan secara alamiah akan membentuk karakter pada diri siswa, dengan kegiatan kepramukaan yang fleksibel dapat dekat dengan masyarakat serta bersifat luas maka lebih efektif dalam pembentukan karakter peduli sosial.

\section{DAFTAR PUSTAKA}

Agustika, N. L. G. M. W. G. N. S. (2020). Intensitas Penggunaan Gadget Oleh Anak Usia Dini. Jurnal Pendidikan Anak Usia Dini, 8(2), 112-120. https://doi.org/10.23887/paud.v8i2.25179.

Amania, M., Nugrahanta, G. A., \& Irine Kurniastuti. (2021). Pengembangan Modul Permainan Tradisional sebagai Upaya Mengembangkan Karakter Adil pada Anak Usia 9-12 Tahun. Elementary School, 8(2), 237-251. https://doi.org/10.31316/esjurnal.v8i2.1230.

Amreta, M. Y. (2018). Pengaruh Kegiatan Pramuka Terhadap Karakter Siswa Madrasah Ibtidaiyah Di Era Digital. Al Ulya: Jurnal Pendidikan Islam, 3(1), 26-38. https://doi.org/10.36840/ulya.v3i1.149.

Amri, S. (2018). Pengaruh Kepercayaan Diri (Self Confidence) Berbasis Ekstrakurikuler Pramuka Terhadap Prestasi Belajar Matematika Siswa Sma Negeri 6Kota Bengkulu. Jurnal Pendidikan Matematika Raflesia, 3(2). https://doi.org/10.33449/jpmr.v3i2.7520.

Arif, M., Rahmayanti, J. D., \& Rahmawati, F. D. (2021). Penanaman Nilai Karakter Peduli Sosial Pada Siswa Sekolah Dasar. Qalamuna -Jurnal Pendidikan, Sosial, Dan Agama, 13(2), 289-308. https://doi.org/10.37680/qalamuna.v13i2.802.

Azizi, A. (2020). Kegiatan Ekstrakurikuler Kepramukaan terhadap Pendidikan Karakter Kedisiplinan. Jurnal Pendidikan Luar Sekolah, 12(2), 40-50. https: //doi.org/10.32832/jpls.v12i2.2793.

Dozan, W., \& Fitriani, L. (2020). Membangun Karakter Anak Usia Dini Melalui Nilai-Nilai Islam Dalam Tradisi Perang Timbung. Murhum. Jurnal Pendidikan Anak Usia Dini, 1(1), 1-15. https://doi.org/10.37985/murhum.v1i1.2.

Fauzi, A., \& Khoiriyah, S. M. (2018). Peran Kegiatan Ekstrakurikuler (Pesantren Sabtu - Ahad) Dalam Menunjang Proses Belajar Mengajar Al-Qur'an Hadits. Jurnal Pendidikan Islam, 13(2), 295 - 306. https://doi.org/10.19105/tjpi.v13i2.1603.

Gazali, N., Cendra, R., Candra, O., Apriani, L., \& Idawati, I. (2019). Penanaman Nilai-Nilai Karakter Peserta Didik Melalui Ekstrakurikuler Pramuka. Aksiologiya: Jurnal Pengabdian Kepada Masyarakat, 3(2), 201. https://doi.org/10.30651/aks.v3i2.1898.

Hero, H. (2020). Implementasi Kegiatan Pramuka dalam Membentuk Karakter Disiplin Siswa Kelas V SD Inpres Boru Kecamatan Wulanggitang Kabupaten Flores Timur. Jurnal Ilmiah Wahana Pendidikan, 6(3), 295307. https://doi.org/10.5281/zenodo.3737983.

Juwantara, R. (2019). Efektivitas ekstrakurikuler Pramuka dalam menanamkan karakter jujur disiplindan bertanggung jawab pada siswa madrasah ibtidaiyah. Premiere Educandum : Jurnal Pendidikan Dasar Dan Pembelajaran, 9(2). https://doi.org/10.25273/pe.v9i2.4994.

Kharisma Bismi Alrasheed, \& Aprianti, M. (2011). Hubungan Antara Kecanduan Gadget Dengan Kecerdasan Emosi Pada Remaja (Sebuah Studi Pada Siswa Smp Di Kecamatan Setiabudi Jakarta Selatan). Jurnal Sains Psikologi, 7(2), 136-142.

Laksono, F. (2018). Pengaruh Ekstrakurikuler Pramuka Terhadap Kedisiplinan dan Kemandirian Siswa. Joyful Learning Journal, 7(1), 70-78. https://doi.org/10.15294/jlj.v7i1.25027.

Mashar, R. (2015). Empati Sebagai Dasar Pembentukan KarakterAnak Usia Dini. In Jurnal Pendidikan Anak (Vol. 2, Issue 2). https://doi.org/10.21831/jpa.v2i2.3040.

Maulida, R., Nadiya, D. Z., Annisa, K., Kusuma, Y., \& Fakhru, L. (2021). Peran Budaya Indonesia Melalui Kegiatan Ekstrakurikuler dalam Pembentukan Karakter di Sekolah Indonesia Kuala Lumpur. METODIK DIDAKTIK:Jurnal Pendidikan Ke-SD-An, 17(1), 19-29. https://doi.org/10.17509/md.v17i1.30569.

Musyarofah, M. (2018). Pengembangan Aspek Sosial Anak Usia Dini Di Taman Kanak-Kanak Aba Iv Mangli Jember Tahun 2016. INJECT (Interdisciplinary Journal of Communication), 2(1), 99. https://doi.org/10.18326/inject.v2i1.99-122.

Nurdin, N., Jahada, J., \& Anhusadar, L. (2021). Membentuk Karakter melalui Kegiatan Ekstrakurikuler Pramuka pada Anak Usia 6-8 Tahun. Jurnal Obsesi: Jurnal Pendidikan Anak Usia Dini, 6(2), 952-959. https://doi.org/10.31004/obsesi.v6i2.1603.

Nurfajriah, S., Netriwati, N., \& Widyastuti, R. (2021). Pengaruh Model Pembelajaran Teams Games Tournament Menggunakan Sandi Semaphore Pramuka Terhadap Kemampuan Pemecahan Masalah Matematis 
Ditinjau dari Tipe Kepribadian Siswa. Jurnal Cendekia : Jurnal Pendidikan Matematika, 5(3), 3178-3189. https://doi.org/10.31004/cendekia.v5i3.825.

Oktavia, N., \& Mulabbiyah, M. (2019). Gawai Dan Kompetensi Sikap Sosial Siswa Mi (Studi Kasus Pada Siswa Kelas V Min 2 Kota Mataram). El Midad, 11(1), 19-40. https://doi.org/10.20414/elmidad.v11i1.1903.

Pangestika, M. D., \& Sabardila, A. (2021). Peningkatan Pendidikan Karakter melalui Ekstrakurikuler Pramuka di SMP Al Islam Kartasura. Pedagogik: Jurnal Pendidikan, 16(1), 25-39. https://doi.org/10.33084/pedagogik.v16i1.1461.

Patria, A., Utaminingsih, S., \& Fathurohman, I. (2021). Pengembangan Buku Cerita Bergambar Berbantuan Video untuk Meningkatkan Karakter Peduli Sosial Siswa Kelas IV SD. Jurnal Studi Guru Dan Pembelajaran, 4(3). https://doi.org/10.30605/jsgp.4.3.2021.1368.

Prihanawati, D. R., \& Hidayah, N. (2018). Pengaruh Keaktifan Mengikuti Ekstrakurikuler Pramuka Terhadap Kemandirian Siswa Kelas V Sd Negeri Cibuk Lor Seyegan Sleman Tahun Ajaran 2017/2018. Jurnal Fundadikdas (Fundamental Pendidikan Dasar), 1(1), 35-44. https://doi.org/10.12928/fundadikdas.v1i1.68.

Putry, R. (2019). Nilai Pendidikan Karakter Anak Di Sekolah Perspektif Kemendiknas. Gender Equality: International Journal of Child and Gender Studies, 4(1), 39. https://doi.org/10.22373/equality.v4i1.4480.

Sari, V. K., Akhwani, A., Hidayat, M. T., \& Rahayu, D. W. (2021). Implementasi Pendidikan Karakter Berbasis NilaiNilai Antikorupsi Melalui Ekstrakurikuler dan Pembiasaan di Sekolah Dasar. Jurnal Basicedu, 5(4), 21062115. https://doi.org/10.31004/basicedu.v5i4.1167.

Sasmito, \& Mustadi. (2015). Developing learners' tematik-integrative worksheet based on character education for primary school students. Jurnal Pendidikan Karakter, 1, 7-8.

Sufanti, M., Nuryatin, A., Rohman, F., \& Waluyo, H. J. (2021). The Content of Tolerance Education in Short Story Learning in High Schools. Asian Journal of University Education, 17(1), 112-123. https://doi.org/10.24191/ajue.v17i1.12609.

Sularso, P. (2017). Upaya Pelestarian Kearifan Lokal Melalui Ekstrakurikuler Karawitan di SMP Negeri 1 Jiwan Tahun 2016. Citizenship Jurnal Pancasila Dan Kewarganegaraan, 5(1), 1. https://doi.org/10.25273/citizenship.v5i1.1181.

Syafitri, S. M. (2020). Menumbuhkan Empati Dan Perilaku Prososial Terhadap Anak Usia Dini Dalam Menanggapi Pelajaran Isu Dunia Nyata. Jurnal Visi Ilmu Pendidikan, 12(2), 140. https://doi.org/10.26418/jvip.v12i2.34049.

Tanto, O. D., Hapidin, H., \& Supena, A. (2019). Penanaman Karakter Anak Usia Dini dalam Kesenian Tradisional Tatah Sungging. Jurnal Obsesi: Jurnal Pendidikan Anak Usia Dini, 3(2), 337-345. https://doi.org/10.31004/obsesi.v3i2.192.

Wahyuni, R., \& Erdiyanti. (2020). Meningkatkan Kemampuan Motorik Halus Anak Melalui Finger Painting Menggunakan Tepung Singkong. Murhum: Jurnal Pendidikan Anak Usia Dini, 1(1), 28-40. https://doi.org/10.37985/murhum.v1i1.5.

Wahyuni, S., Isnarto, \& Wuryanto. (2015). Pengembangan Karakter Kedisiplinan Dan Kemampuan Pemecahan Masalah Melalui Model Laps-Heuristik Materi Lingkaran Kelas-Viii. Unnes Journal of Mathematics Education, 4(2). https://doi.org/10.15294/ujme.v4i2.7594.

Widiyono, A. (2020). Efektifitas Perkuliahan Daring (Online) pada Mahasiswa PGSD di Saat Pandemi Covid 19. Jurnal Pendidikan, 8(2), 169-177. https://doi.org/10.36232/pendidikan.v8i2.458. 